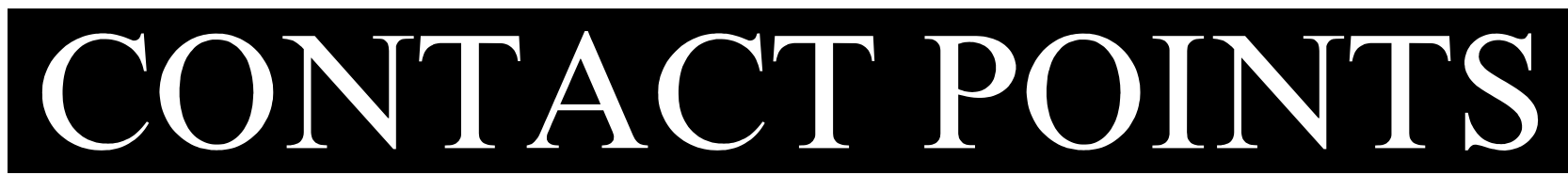

\section{Contact dermatitis} associated with Astronium urundeuva (allemão) Engl., a traditional medicinal plant from Brazil

Maria Do Livramento L. Vilar ${ }^{1}$, Maria José Nogueira Diógenes ${ }^{1}$, Janaina L. Vilar ${ }^{2}$, José G. Bezerra Filho ${ }^{1}$, Joana D'arc Pereira Dantas, Júlia Aparecida L. De Souza and Selene Maia de Morais ${ }^{2}$

${ }^{1}$ Hospital Universitário Walter Cantídio, Universidade Federal do Ceará Fortaleza, and ${ }^{2}$ Departamento de Química da Universidade Estadual de Ceará, Fortaleza, Ceará, Brazil

Key words: Anacardiaceae; Astronium urundeuva; contact dermatitis; medicinal plants.

Astronium urundeuva (allemão) Engl. (Anacardiaceae) is used in northeastern Brazilian folk medicine largely for the treatment of gynaecological and dermatological problems (1). Previous studies of this plant have shown antiulcerogenic (2), analgesic and anti-inflammatory $(3,4)$ effects. In clinical practice, there is anecdotal evidence that the use of $A$. urundeuva in topical preparations may cause, maintain or worsen cutaneous lesions, such as acute, subacute and chronic dermatitis. The present study deals with the preparation of extracts of $A$. urundeuva to be used in patch tests to determine prevalence of sensitivity and the dominant allergens involved with sensitization.

It was accomplished in a transverse study of cases of contact dermatitis and sensitization to A. urundeuva in 137 patients attended at Dermatology Center of Walter Cantídio University Hospital/Federal University of Ceará, Brazil. The patients were submitted to patch test using hexane and ethanol extract of $A$. urundeuva and derived fractions. The plant was collected in Meruoca Hill, situated in Ceará State, and identified by Dr Afrânio Fernandes from the Prisco Bezerra Herbarium of Federal University of Ceará, where a voucher specimen is deposited under number 29851. The patch testing was preceded by anamnese and physical examination then applied using: Standard series (PATCHKIT STANDARD ${ }^{\circledR}-$ FDA Allergenic), hexane and ethanol extracts in $2.5 \%, 5 \%$ and $10 \%$; fractions of the hexane (Aur1, Aur2) and ethanol extracts (Aur3, Aur4) in $1 \%$ and $2 \%$ and cardol in $1 \%$ concentrations. All the samples and the constituents of the complementary series were diluted in ethyl alcohol $\left(92.8^{\circ}\right)$ that was used as negative control. 3 of $137(2 \%)$ patients showed 1 or more positive reactions to the hexane and ethanol extracts and fractions of A. urundeuva in the patch tests.

Patient 1 had a positive test to $5 \%$ and $10 \%$ EtOH extract. He reported using topical preparation of $A$. urundeuva to treat a cutaneous rash, but instead of improvement, had accentuation of the lesions. Lesions resolved once treatment with the A. urundeuva preparation was stopped. Patient 2 showed positive results for the hexane extract, fraction Aur4 $(2 \%)$ and cardol $(1 \%)$. The patient also reported an improvement of the dermatitis, after suspension of topical use of A. urundeuva. Patient 3 had positive results with the fractions Aur3 (1\%) and Aur4 (2\%). Phytochemical tests (5) were performed with the fractions Aur1 and Aur2 which were classified as triterpenes; Aur3 showed to contain flavonoids and Aur4 contains pyrogallic tannins. In conclusion, ethanol soluble extractives and to a lesser extent hexane soluble extractives from the bark of $A$. urundeuva are capable of eliciting positive patch test reactions in persons who have apparently become sensitized to the plant material following its topical use.

\section{References}

1. Matos F J A. Plantas Medicinais Guia de seleção e emprego de plantas medicinais do Nordeste do Brasil. Fortaleza: IOCE, 1989: 1: 164p.

2. Rao V S N, Viana G S B V, Menezes A M S, Gadelha M G T. Studies on the anti-ulcerogenic activity of Astronium urundeuva Engl. Braz J Med Biol Res 1987: 20: 803-805.

3. Viana G S B V, Bandeira M A M, Matos F J A. Analgesic and antiinflamatory effects of chalcones isolated from Myradrodruon urundeuva Allemão. Phytomedicine 2003: 10: 189-195.

4. Menezes A M S, Rao V S N, Fonteles M C. Antitinflammatory activity of Astronium urundeuva: possible mechanisms envolved. Braz $J$ Med Biol Res 1985: 18: 861-864.

5. Matos F J A. Introdução À Fitoquimica Experimental. Fortaleza: EUFC, 1988, 128.

Address:

Selene Maia de Morais

Rua Ana Bilhar, 601, Apto 400,

Meireles, CEP: 60160-110,

Fortaleza, Ceará, Brazil

e-mail:selene@uece.br

\section{Allergic contact dermatitis due to Opuntia ficus-indica var. saboten}

Ho Joon Yoon, Chong Hyun Won and Sang Eun Moon

Department of Dermatology, Seoul National University College of Medicine, Seoul, Korea

Key words: allergic contact dermatitis; Opuntia ficus-indica var. saboten; patch testing; plants.

\section{Case Report}

A 43-year-old woman had an erythematous skin lesion on her left shoulder 4 weeks ago. Initially, she had noticed a skin lesion with foul odour on the left shoulder 2 months ago. She had applied a sliced fruit 
of Opuntia ficus-indica var. saboten as a folk remedy 6 weeks ago and removed it after 1 week. There were no side-effects on her skin at that time, hence she re-applied it 4 weeks ago. Within a day, she developed an erythematous plaque with exudation followed by itching. She had a history of allergic contact dermatitis from lacquer tree 28 years ago. The skin lesion improved with topical and systemic corticosteroids and did not recur after discontinuing the use of Opuntia ficus-indica var. saboten fruit.

Patch testing was performed with the Korean standard series and with Opuntia ficus-indica var. saboten fruit as is. Readings at day 2 /day 4 showed a strong $(++)$ positive reaction to Opuntia ficus-indica var. saboten fruit. We performed patch testing with Opuntia ficus-indica var. saboten fruit in 12 healthy adults ( 5 male and 7 female, mean age 34.5 years) to confirm a real allergic contact dermatitis, not a false positive irritant reaction. They all showed no reaction to Opuntia ficus-indica var. saboten fruit at day 2 /day 4.

\section{Discussion}

The prickly pear cactus (Opuntia ficus-indica) has a global distribution and is an important nutrient and food source (1). Mexicans have long used Opuntia leaves and fruits for their medicinal benefits, such as for treating arteriosclerosis, diabetes, gastritis and hyperglycaemia (2). The prickly pear variety Opuntia ficus-indica var. saboten is widely cultivated on Cheju Island, which is in southwestern Korea, and is eaten as a food in Korea. The components of its fruit are flavonoids, alkaloids, polypeptides, $\beta$-sitosterol, saponin, anhalinin, isobetaine, betaine and others (3). Recent studies have shown that this plant has antimicrobial (4) and antioxidant properties (5) and possesses an inhibitory action on gastric lesions (6).

Opuntia spp. are well known inducers of mechanical irritant contact dermatitis (7). The small glochids cause dermatological problems by physical penetration into the skin. Allergic contact dermatitis from Opuntia ficus-indica var. saboten has not previously been reported, although it is widely used in folk medicine. The components of its fruit are rare sensitizers. We were unable to determine precisely which component induced her skin lesion. Our patient had previously been sensitized to lacquer tree, a well known sensitizer, but there is no known cross-reaction between lacquer tree and Opuntia spp.

Our case shows that allergic contact reaction from Opuntia ficus-indica var. saboten fruit can occur. Hence, we advise a period of observation after applying of its fruit for medicinal benefits.

\section{References}

1. El Kossori $\mathrm{R}$ L, Villaume $\mathrm{C}$, El Boustani E, Sauvaire Y, Mejean L. Composition of pulp, skin and seeds of prickly pears fruit (Opuntia ficus-indica sp). Plant Foods HUM Nutr 1998: 52: 263-270.

2. Gurrieri S, Miceli L, Lanza C M, Tomaselli F, Bonomo R P, Rizzarelli E. Chemical characterization of sicilian prickly pear (Opuntia ficus-indica) and perspectives for the storage of its juice. J Agric Food Chem 2000: 48: 5424-5431

3. Park E H, Chun M J. Wound healing activity of Opuntia ficus-indica. Fitoterapia 2001: 72: 165-167.

4. Kim S H, Kwon N H, Kim Y J et al. Antimicrobial activity of natural product made by Opuntia ficus-indica var. saboten against salmonella spp. and Escherichia coli O157:H7 J Food Hyg Safety 2002: 17: 71-78.

5. Lee J C, Kim H R, Kim J, Jang Y S. Antioxidant property of an ethanol extract of the stem of Opuntia ficusindica var saboten. J Agric Food Chem 2002: 50: 6490-6496.

6. Lee E B, Hyun J E, Li D W, Moon Y I. The effect of Opuntia ficus-indica var. saboten fruit on gastric lesion and ulcer in rats. Natural Product Sci 2001: 7: 90-93.

7. McGovern T W, Barkley T M. Botanical briefs: prickly pear cactus Opuntia miller. Cutis 2001: 68: 188-190.

Address:

Sang Eun Moon

Department of Dermatology

Seoul National University Boramae Hospital

425 Sindaebang-dong

Dongjak-gu

Seoul

Korea

Tel: +8228402190

Fax: +8228312826

e-mail: semoon@snu.ac.kr
Allergic contact dermatitis from cinnamic aldehyde found in an industrial odour-masking agent

Timothy J. Decapite ${ }^{1}$ and Bryan E Anderson ${ }^{2}$

${ }^{1}$ University of Maryland, College Park, MD, and ${ }^{2}$ Department of Dermatology, Penn State University, Hershey, PA, USA

Key words: allergic contact dermatitis; cinnamic aldehyde; occupational; vinyl.

\section{Case Report}

A 47-year-old man suffered from dermatitis of his hands, feet, face and body for 12 years prior to presentation. He had worked at an industrial plant for 23 years handling vinyl covers used for car seat upholstery. He routinely handled a powder used to mask the vinyl odour. His dermatitis was mildly improved with the use of topical clobetasol ointment.

Physical examination showed illdefined scaling plaques with fissures on both hands and pink patches on the face and eyelids.

Patch testing with the North American Contact Dermatitis Group standard series was performed. The day 2 readings showed positive reactions to neomycin sulfate $(++)$, Myroxylon pereirae $(+)$, bacitracin $(++)$, cinnamic aldehyde $(+)$ and fragrance mix $(++)$. Review of the material and safety data sheets of the chemicals the patient was exposed to showed that cinnamic aldehyde was present in the product BP Reodorant 350 (Alpine Aromatics International, Piscataway, NJ, USA). This was the powder used to mask the vinyl odour of the products the patient handled. At a 9-month follow-up appointment, the patient's symptoms had improved with avoidance of the offending agent.

\section{Comment}

Cinnamic aldehyde is the presumed cause of this patient's contact dermatitis. He had been exposed to this chemical for years, and his symptoms improved with avoidance of the allergen. 
Cinnamic aldehyde is a relatively common cause of allergic contact dermatitis (1). It is used as a fragrance and flavouring in many different products, including perfumes, toothpastes, spices and cosmetics $(2,3)$. To date, no cases have been reported of cinnamic aldehyde as a cause of dermatitis, when used as a fragrance in the industrial product BP Reodorant 350. This allergy should be considered in plant workers with dermatitis and exposure to industrial fragrances. In addition, due to the fact that cinnamic aldehyde is used as a masking agent, those who handle vinyl treated with BP Reodorant 350 compound are at risk of developing contact allergy to cinnamic aldehyde.

\section{References}

1. Frosch R J, Johansen J D, Menne T et al. Further important sensitizers in patients sensitive to fragrances. Contact Dermatitis 2002: 47: 78-85.

2. Bruze M, Johansen J D, Andersen K E et al. Deodorants: an experimental provocation study with cinnamic aldehyde. J Am Acad Dermatol 2003: 48: 194-200.

3. Drake T E, Maibach H I. Allergic contact dermatitis and stomatitis caused by a cinnamic aldehyde-flavored toothpaste. Arch Dermatol 1976: 112: 202-203.

\section{Address:}

Bryan E Anderson, MD

Assistant Professor of Dermatology

Penn State University

PO Box 850

500 University Drive

UPC II, Suite 4300

Hershey, PA 17033

USA

Tel: +17175318307

Fax: +17175316516

e-mail:banderson@psu.edu

Mesalazine and paraphenylenediamine allergy

J. Charles ${ }^{1}$, J. L. Bourrain ${ }^{1}$, A. Tessier ${ }^{2}$, J. P. Lepoittevin ${ }^{3}$ and J. C. Beani ${ }^{1}$

${ }^{1}$ Dermatologie, Département Pluridisciplinaire de Médecine, ${ }^{2}$ Département de Pharmacie, CHU de Grenoble, BP 217, 38043 Grenoble Cedex 9 , and ${ }^{3}$ Laboratoire de Dermatochimie, Clinique Dermatologique, Université Louis Pasteur, CHU, 67091 Strasbourg, France
Key words: allergy; 'baboon syndrome'; cross-sensitivity; drug eruption; mesalazine; para-phenylenediamine.

\section{Case Report}

In 1994, a 40-year-old woman suffering from ulcerative colitis presented with a cutaneous reaction to a treatment regimen combining mesalazine, $1500 \mathrm{mg}$ orally $\times 3$ a day, and corticosteroid-based intrarectal injections. A pruritic erythematous eruption affecting the pelvic area and buttocks occurred after the 1st dose. Suspecting allergy to mesalazine, the treatment was stopped immediately and the patient referred to a dermatoallergology unit to identify the allergy. The patient, a former hairdresser, had already had cutaneous eruptions linked to the use of haircolouring products and various drugs: amoxicillin, clindamycin and fenoprofen.

Patch tests were carried out on 12 August 2003: they included the European standard series and mesalazine diluted to $10 \%$ in water and pet. The 2 patch test with mesalazine were negative at day 2 , those with paraphenylenediamine (PPD) and nickel being positive.

A test of oral reintroduction of mesalazine was carried out under clinical supervision 1 month later along the following lines - mesalazine was to be reintroduced orally by gradual doses at $30 \mathrm{~min}$ intervals: a $10 \mathrm{mg}$ to $1 \mathrm{~g}$ dose in the morning of day 1 , followed by only 1 dose in the afternoon of day 2 and finally 3 times $1 \mathrm{~g}$ within $3 \mathrm{hr}$ on day 2 . A pruriginous rash appeared on the chest and neck at the 6th hour after an overall dose of $2860 \mathrm{mg}$ causing the test to be stopped. After $24 \mathrm{hr}$, the eruption persisting, the patch tests with mesalazine and PPD carried out 1 month earlier were activated and reactivated, respectively.

\section{Discussion}

Mesalazine is not known to show cross-reactivity in the case of sensitivity to PPD. This drug is commonly prescribed in the treatment of ulcerative colitis, especially as an alternative to sulfasalazine in the case of intolerance. A retrospective study of side-effects related to mesalazine from 1991 to 1998 in UK identified 14 cutaneous reactions per 2.8 million prescriptions, a figure which remains low in spite of the fact that not all cases are likely to have been reported (1). In our patient's case, an eruption during the reintroduction test was followed by activation/reactivation of the mesalazine patch tests and that of PPD, pointing to a link between sensitivity to PPD and mesalazine. Moreover, the laboratory which produces mesalazine has informed us that chromatographic identification of the components of the medicine showed para-aminophenol traces as impurities at levels of $0.01 \%$ or less, para-aminophenol being a para-amino compound known to cross-react with PPD (2). Besides, para-aminophenol may have been produced in vivo through the decarboxylation of mesalazine.

Although the common hapten has not been identified, it may have been semiquinone-imine, a product resulting from oxidation of para-aminophenol and the 1st hydrolysis product of quinone-imine derived from PPD, or again benzoquinone, which is the first hydrolysis product of semiquinone-imine (3). This unusual plausible cross-reaction further argues in favour of the fact that patients are not sensitive to the same metabolites and that consequently cross-reactions within the large para-amino family are variable. Concerning our patient's 1994 cutaneous reaction, the initial topography hinting at a 'baboon syndrome' and the relapse during drug reintroduction, combined with reactivation of a previously positive patch test, that to PPD, point to systemic contact dermatitis (4).

We advocated the avoidance of both mesalazine and para-amino compounds. Oral hyposensitization to mesalazine was not attempted as this is usually proposed in anaphylactic or anaphylactoid reactions, whereas we were dealing here with a cellular hypersensitivity probably linked to previous sensitization to PPD (5). In future cases of allergy to mesalazine, it would be advisable to patch test with PPD to find out whether such cross-sensitivity is the exception or the rule, sensitivity to PPD occurring frequently in the population at large nowadays, mainly due to hair-colouring products and 'black henna' tattoos (6). 


\section{References}

1. Ransford R A, Langman M J. Sulphasalasine and mesalazine: serious adverse reactions re-evaluated on the basis of suspected adverse reactions reports to the Committee on Safety of Medecines. Gut 2002: 51: 536-539.

2. Uter W, Richter G. The spectrum of (cross-)sensitivity in clinical patch testing with "para amino" compounds. Allergy 2002: 57: 319-322.

3. Lisi P, Hansel K. Is benzoquinone the prohapten in cross-sensitivity among aminobenzene compounds? Contact Dermatitis 1998: 39: 304-306.

4. Menné T, Veien N K. Systemic contact dermatitis. In: Textbook of contact dermatitis, 3rd edition. Rycroft R J G, Menné T, Frosch P J, Lepoittevin J P (eds), Berlin, Springer, 2001: 357-366.

5. Varela S, Menedez M. Oral desensitization to 5-ASA. Allergy 2002: 57: 371-372.

6. Le Coz C J, Grosshans E. Allergic contact dermatitis caused by skin painting (pseudotattooing) with black henna, a mixture of henna and p-phenylènediamine and its derivatives. Arch Dermatol 2000: 136: 1515-1517.

Address:

$J$ Luc Bourrain

Dermatologie-Allergologie

Département Pluridisciplinaire de

Médecine

CHU de Grenoble

BP 217

38043 Grenoble Cedex 9

France

Tel: +33476765508

Fax: +33476765558

e-mail: jlbourrain@chu-grenoble.fr

Occupational contact dermatitis from 2,4dinitrofluorobenzene

Alfonso Perez, Shalini Narayan and Jane Sansom

Bristol Dermatology Centre, Bristol Royal Infirmary, Bristol BS2 8HW, UK

Key words: allergic contact dermatitis; 2,4-dinitrofluorobenzene; occupational; pesticides.

\section{Case Report}

A 53-year-old chemical plant technician presented with acute widespread dermatitis requiring inpatient treatment with topical clobetasol propionate $0.05 \%$ and oral corticosteroid. 2 days earlier he had developed an eruption on the right knee. A week prior to this, he had dismantled a vessel containing chemicals used in the manufacturing of pesticides. $\mathrm{He}$ had initially worn a butyl rubber suit. A colleague had cleared a blockage in the vessel, and he had returned to re-assemble the vessel, wearing only overalls, under the impression that no hazardous chemicals were present.

Patch testing was performed 3 months after the incident, including samples provided by the company. He was patch tested to an extended British standard series and a cosmetics/preservatives series, as well as to 2,4-dinitrochlorobenzene and 2,4dinitrofluorobenzene at a range of concentrations $\quad(0.0001 \%, \quad 0.001 \%$ and $0.01 \%$ in acetone). He had a positive reaction $(\mathrm{D} 2+/ \mathrm{D} 4++)$ to $0.01 \%$ 2,4-difluoronitrobenzene only.

\section{Discussion}

2,4-dinitrofluorobenzene is used as an intermediate in the synthesis of pesticides (algicides) and some pharmaceuticals such as flurbiprofen (an NSAID). It is also used as a sensitizing agent and hapten in laboratory immunology and as a reagent (Sanger's reagent) to identify the terminal amino acids in a protein chain $(1,2)$.

To our knowledge, this is the first report of allergic contact dermatitis from 2,4-dinitrofluorobenzene in the pesticides industry. Garcia-Perez (3) reported a case of contact dermatitis in a research biochemist provoked by the Sanger reagent (2,4-dinitrofluorobenzene). In this case, the initial tests with dinitrofluorobenzene were negative, but further testing with freshly prepared material was positive. The author postulated that the high instability of the reagent, producing skin sensitivity only when freshly prepared, explained the surprisingly few cases of this occupational dermatitis considering its widespread use in biochemical research.

2,4-dinitrochlorobenzene causing allergic contact dermatitis is well described. Adams et al. (4) reported 4 cases of contact dermatitis in airconditioning repairmen due to 2,4dinitrochlorobenzene used as an algicide for cooling water. Finally, Garcia-Perez reports cross-sensitization between these dinitrobenzene derivatives. This did not occur in our patient who showed a positive reac- tion to dinitrofluorobenzene but not to dinitrochlorobenzene.

\section{References}

1. http://chemicalland21.com.

2. Wang H, Tedla N, Lloyd A R et al. Mast cell activation and migration to lymph nodes during induction of an immune response in mice. $J$ Clin Invest 1998: 102: 1617-1626.

3. Garcia-Perez A. Occupational dermatitis from DNFB with cross sensitivity to DNCB. Contact Dermatitis 1978: 4: 125-127.

4. Adams R M, Zimmerman M C, Bartlett J B. 1-Chloro-2,4-dinitrobenzene as an algicide. Report of four cases of contact dermatitis. Arch Dermatol 1971: 103: 191-193.

Address:

Alfonso Perez

St John's Institute

St Thomas' Hospital

Lambeth Palace Road

London, SE1 7EH

$U K$

Tel: +442071887188

Fax: +442071886270

e-mail: alfonsoperezdeve@aol.com

Contact allergy to spearmint oil in a patient with oral lichen planus

\section{R. Clayton and D. Orton}

Department of Dermatology, Amersham Hospital, Whielden Street, Amersham, Buckinghamshire, UK

Key words: contact stomatitis; Gengigel ${ }^{\circledR}$; oral lichen planus; spearmint oil.

A 78-year-old woman with a 3-year history of oral lichen planus was referred by her dental practitioner for patch testing to exclude an allergic contact stomatitis from amalgam. Her symptoms consisted of intermittent oral erosions, loss of taste and oral soreness that were exacerbated by various dentifrices.

She was patch tested to the departmental standard and dental series as well as to the different mint oils (menthol 1\% pet., spearmint oil $1 \%$ pet. and peppermint oil $1 \%$ pet.). She had no reactions to the dental series including amalgam and mercury salts but had 
positive reaction to spearmint oil $1 \%$ pet. on day 4 .

\section{Discussion}

Contact allergy from spearmint oil is rare. There are only a handful of reports of spearmint oil causing a contact cheilitis, when it has been a constituent of toothpaste (1-3), and there is a single case report of it causing a contact dermatitis following its application to the skin for pain relief (4).

This patient was using Gengigel ${ }^{\circledR}$ mouth rinse as advised by her dental practitioner to help with her symptoms, as well as chewing gum which contained spearmint. Gengigel ${ }^{\mathrm{R}}$ mouth rinse is a hyaluronic acid preparation that is recommended by dental practitioners to protect against gingivitis, stomatitis and periodontitis. The manufacturer (Ricerfarma, Milan, Italy) confirmed that it contained spearmint oil. Avoidance of this mouth rinse, as well as all dentifrices and chewing gums that contained spearmint oil, has led to a dramatic improvement in the discomfort. She is still left with evidence of oral lichen planus.

To our knowledge, this is the first case of an allergic contact stomatitis from spearmint oil to be reported in a patient with known oral lichen planus. This case illustrates that it may still be important to exclude a superimposed allergic component to a problem and, in particular, when a patient gives a supportive clinical history.

\section{References}

1. Skrebova N, Brocks K, Karlsmark T. Allergic contact cheilitis from spearmint oil. Contact Dermatitis 1998: 39: 35.

2. Andersen K E. Contact allergy to toothpaste flavours. Contact Dermatitis 1978: 4: 195-198.

3. Francalanci S, Sertoli A, Giorgini S, Pigatto P, Santucci B, Valsecchi R. Multicentre study of allergic contact cheilitis from toothpastes. Contact Dermatitis 2000: 43: 216222.

4. Bonamonte D, Mundo L, Daddabbo M, Foti C. Allergic contact dermatitis from Mentha spicata (spearmint). Contact Dermatitis 2001: 45: 298.

Address:

R. Clayton

Department of Dermatology

Amersham Hospital
Whielden Street

Amersham

Buckinghamshire

HP7 OJD

$U K$

Tel: +44 1494734600

Fax: +44 1494734662

e-mail:r.clayton@doctors.org.uk preparations of methyldibromo glutaronitrile in petrolatum

Birgitta Gruvberger, Margareta Bjerkemo and Magnus Bruze

Department of Occupational and Environmental Dermatology, Malmö University Hospital, Malmö, Sweden

Key words: antimicrobials; biocides: methyldibromo glutaronitrile; patch testing technique; petrolatum; preservatives.

For any contact sensitizer included in a patch test series or tested as a stored preparation, the stability of the sensitizer should be known to avoid falsenegative test reactions (1). To help determine the optimal test preparation for methyldibromo glutaronitrile (MDBGN), 4 petrolatum preparations of MDBGN at $1.0 \%, 0.5 \%$, $0.3 \%$ and $0.1 \%$ were patch tested in 2661 consecutive dermatitis patients at 11 clinics representing 9 European countries (2). Chemical analyses of the preparations were performed when fresh and 1 year old.

\section{Materials and Methods}

MDBGN was kindly provided by Schülke and Mayr, Hamburg, Germany. From the same batch,
Stability of patch test
MDBGN preparations in petrolatum at $1.0 \%, 0.5 \%, 0.3 \%$ and $0.1 \% \mathrm{w} / \mathrm{w}$ were made by, and purchased from, Chemotechnique Diagnostics (Malmö, Sweden). The preparations were then stored in a refrigerator $\left(6-8^{\circ} \mathrm{C}\right)$ for 1 year. The following solvents were used: $n$-heptane and methanol, both of high-performance liquid chromatography (HPLC) quality (LabScan, Dublin, Ireland) and Milli-Q-filtered water.

\section{Sample preparation}

Before HPLC analysis, an extraction procedure at room temperature was performed. About $0.5 \mathrm{~g}$ of a test preparation was accurately weighed and placed in a 10-ml glass tube with a screw cap, and $8.0 \mathrm{ml} n$-heptane was added. The mixture was shaken vigorously for $1 \mathrm{~min}$ and then placed in a separating funnel. The tube was rinsed with $3 \times 10 \mathrm{ml}$ of $n$-heptane, which was then added together with $20.0 \mathrm{ml}$ methanol/ water $(90 / 10 \mathrm{v} / \mathrm{v})$ to the separating funnel, before shaking it and removing the underphase. The extraction procedure was repeated 4 times, and the methanol/water phases were collected in a 100-ml volumetric flask and filled up to $100.0 \mathrm{ml}$ with methanol/water $90 / 10$.

\section{High-performance liquid chromatography}

An isocratic HPLC system consisting of an SP Spectra Series P200 pump, an SP Spectra System UV 1000 detector and an SP ChromJet integrator was used. The system was equipped with a Rheodyne 7125 injector (Rheodyne, Cotati, CA, USA) and with a $20-\mu$ loop. The column $(4.6 \mathrm{~mm}$ i.d. $\times 250 \mathrm{~mm})$ was packed with 5- $\mu \mathrm{m}$ Kromasil $\mathrm{C}_{18}$. The UV detector was operated at a wave-
Table 1. Results of high-performance liquid chromatography analyses of test preparations with methyldibromo glutaronitrile (MDBGN) at 4 concentrations in petrolatum when fresh and 1 year old

\begin{tabular}{lll}
\hline & \multicolumn{2}{l}{ Detected concentration of MDBGN \%w/w } \\
\cline { 2 - 3 } MDBGN \%w/w & Fresh preparation & 1-year-old preparation \\
\hline 1.0 & $0.88(0.86-0.90)$ & $0.88(0.88-0.88)$ \\
0.5 & $0.46(0.43-0.48)$ & $0.46(0.45-0.46)$ \\
0.3 & $0.27(0.27-0.27)$ & $0.27(0.26-0.28)$ \\
0.1 & $0.09(0.09-0.09)$ & $0.09(0.09-0.09)$ \\
\hline
\end{tabular}

The values are given as mean (range).

Mean concentration is based on 4 and 3 analyses of the fresh and 1-year-old preparation, respectively. 
length of $220 \mathrm{~nm}$. The flow rate was $1.0 \mathrm{ml} / \mathrm{min}$. The mobile phase was methanol/water 40/60 (v/v).

The test preparations were analysed at time 0 and after 1 year.

\section{Results and Discussion}

For practical and stability reasons, petrolatum is the preferred patch test vehicle for most sensitizers. Many compounds are stable for years when kept in a refrigerator at $4^{\circ} \mathrm{C}$, prepared in a vehicle like petrolatum (3), though there are exceptions $(4,5)$. However, MDBGN is no exception, as Table 1 summarizes that MDBGN in petrolatum at the 4 investigated concentrations is stable, without any sign of degradation after storage for 1 year in a refrigerator. Furthermore, the variation in concentrations found between samples from 1 and the same test preparation on 1 occasion is small (Table 1), demonstrating that there is no need to add any emulsifier to distribute MDBGN evenly in petrolatum.

\section{References}

1. Bruze M, Conde-Salazar L, Goossens A, Kanerva L, White I R. Thoughts on sensitizers in a standard patch test series. The European Society of Contact Dermatitis. Contact Dermatitis 1999: 41: 241-250.

2. Gruvberger B, Andersen K E, Brandao $\mathrm{F}$ M et al. Patch testing with methyldibromoglutaronitrile, a multicenter study within EECDRG (in press).

3. Andersen $\mathrm{K}$ E, Rastogi S C, Carlsen L. The Allergen Bank: a source of extra contact allergens for the dermatologist in practice. Acta Derm Venereol 1996: 76: 136-140.

4. Eriksam U, Bruze M, Goossens A. Degradation of triglycidyl isocyanurate as a cause of false-negative patch test reaction. Contact Dermatitis 2001: 44: 13-17.

5. Frick M, Zimerson E, Karlsson D, Marand $\AA$, Skarping G, Isaksson M, Bruze M. Poor correlation between stated and found concentrations of diphenylmethane- $4,4^{\prime}$-diisocyanate in petrolatum patch-test preparations. Contact Dermatitis 2004 (in press).

Address:

Birgitta Gruvberger

Department of Occupational and

Environmental Dermatology

Malmö University Hospital

S-205 02 Malmö

Sweden

Tel: +4640331759

Fax: +4640336213

e-mail: birgitta.gruvberger@skane.se
Contact sensitivity to rhodium and iridium in consecutively patch tested subjects
L. Stingeni, L. Brunelli and P. Lisi

Section of Clinical, Allergological and

Environmental Dermatology, Department of Medical and Surgical Specialities, University of Perugia, Perugia, Italy

Key words: contact sensitivity; iridium; metals; patch testing; rhodium.

Naturally occurring metals and their man-made compounds are the most important contact allergens in the general population, as well as in occupational settings (1). However, little is known about the sensitizing capacity of rhodium and iridium. These are 2 metals of the platinum group belonging to the same group $\left(9^{\text {th }}\right)$ but to different periods $\left(5^{\text {th }}\right.$ and $6^{\text {th }}$, respectively) of the periodic table of elements. Both are considered allergologically safe, although there are a few reports of both occupational $(2,3)$ and non-occupational $(4,5)$ delayed sensitivity, as well as a case of contact urticaria with respiratory tract symptoms caused by occupational exposure (6).

In this study, the frequency and relevance of positive reactions to rhodium and iridium in 720 consecutively patch tested patients were investigated.

\section{Patients and Methods}

From March 2001 to September 2002, 720 consecutive informed eczematous patients were patch tested with the SIDAPA (Italian Society of Allergological, Occupational and Environmental Dermatology) standard series, $1 \%$ rhodium chloride and $1 \%$ iridium chloride, both in water. The patch tests were performed with van der Bend square chambers ${ }^{\circledR}$ (van der Bend B.V., Brielle, the Netherlands) on Scanpor ${ }^{\mathbb{B}}$ tape (Norgesplaster, Kristiansand, Norway), reinforced with Soffix plaster ${ }^{\mathbb{B}}$ (Artsana, Grandate, Italy) and applied for 2 days on the upper back. Readings were made 30 min after patch removal (day 2) and 2 days later (day 4), according to the GIRDCA (Italian Research Group of
Contact and Environmental Dermatitis) criteria (7). Only ++ and +++ reactions were accepted as positive, excluding follicular, pustular, purpuric and/or 'porotic' reactions.

\section{Results}

None of the 720 patch tested subjects showed positive or irritant reactions to iridium chloride, but 2 were found to have a positive patch test to rhodium chloride as well as other metals (Table 1 ). The $1^{\text {st }}$ patient reported contact dermatitis from metallic clothing accessories; the $2^{\text {nd }}$ presented with chronic foot dermatitis from shoes. Neither of the subjects suffered from hand dermatitis.

\section{Discussion}

Rhodium and iridium have various applications in both occupational and non-occupational activities. Rhodium, discovered by Wollastrom in the early $19^{\text {th }}$ century in crude platinum ore, occurs natively in river sands of the Urals and in North and South America. It is highly reflective, durable and resistant to corrosion. Rhodium is primarily used as an alloying agent to harden platinum and palladium (high temperature thermocoupling elements, bushings for glass fibre production, electrodes for aircraft spark plugs) and as a catalyst in nitrogen oxide combustion of ammonia. It is also found in electrical material because of its low electrical and contact resistance, in jewellery (platings of silver or white gold because of its silvery white colour), in optical instruments and dental prostheses. Iridium, identified by Tennant in 1803 in the residue left when crude platinum was dissolved in aqua regia, is present in alluvial deposits. It is very hard and brittle, making it difficult to work. For its catalytic properties, iridium is commonly used in electrochemical industries and for its chemical resistance in amalgams and/ or in white gold used in dental practice.

Our study results confirm that rhodium and, above all, iridium are allergologically safe (8), even in patients sensitized to metals. 1 or 
Table 1. Patch test results

\begin{tabular}{llllll}
\hline & & & \multicolumn{2}{l}{ Simultaneous positive reactions } \\
\cline { 3 - 7 } Patient number & Age (years)/sex & Rhodium chloride $(1 \%$ aq. $)$ & $\begin{array}{l}\text { Nickel sulfate } \\
(5 \% \text { pet. })\end{array}$ & $\begin{array}{l}\text { Cobalt chloride } \\
(1 \% \text { pet. })\end{array}$ & $\begin{array}{l}\text { Potassium dichromate } \\
(0.5 \% \text { pet. })\end{array}$ \\
\hline 1 & $38 /$ female & ++ & +++ & ++ & - \\
2 & $48 /$ male & ++ & ++ & ++ & ++ \\
\hline
\end{tabular}

more positive reactions to metals were observed in $30.4 \%$ of the 720 patch tested patients (nickel sulfate: $27.5 \%$; potassium dichromate: $8.1 \%$; cobalt chloride: $7.5 \%$ ), though only 2 of these were positive to rhodium.

Rhodium and iridium are sometimes reported as sensitizers in the form of salts, though not as metals, in subjects employed in precious metals or jewellery industries $(2,3)$ or with dental amalgams or prostheses $(4,5)$. Nevertheless, the use of these metals is limited due to their high costs on the world market and also perhaps because rhodium plating does not seem to prevent nickel release from jewellery, as shown by Vilanova and GiménezCamarasa (9) and, more recently, by Foti et al. (10).

The relevance of positive reactions to rhodium in our 2 patients remained unexplained. Patient no. 1 was a nurse and patient no. 2 an ecological operator; neither had metallic dental prostheses or amalgams. As chemical analysis (mass spectrometry) of rhodium chloride used for patch testing did not detect traces of nickel and/or cobalt, we excluded a false-positive reaction to rhodium due to contaminants.

In conclusion, despite their low sensitization potential, we believe that rhodium and iridium salts should be included in screening series for patch testing subjects who work in the jewellery and precious metals industries, or who are suffering from gingivostomatitis.

\section{References}

1. Lidén C, Bruze M, Menné T. Metals. In: Textbook of Contact Dermatitis, 3rd edition. Rycroft R J G, Menné T, Frosch P J, Lepoittevin J-P (eds), Berlin, Springer Verlag, 2001: 933-977.
2. Bedello P G, Goitre M, Roncarolo G, Cane D. Contact dermatitis to rhodium. Contact Dermatitis 1987: 17: 111-112.

3. De La Cuadra J, Grau-Massanés M. Occupational contact dermatitis from rhodium and cobalt. Contact Dermatitis 1991: 25: 182-184.

4. Vilaplana J, Romaguera Cornellana F. Contact dermatitis and adverse oral mucous membrane reactions related to the use of dental prostheses. Contact Dermatitis 1994: 30: 80-84.

5. Marcusson J A, Cederbrant K, Heilborn J. Indium and iridium allergy in patients exposed to dental alloys. Contact Dermatitis 1998: 38: 297-298.

6. Bergman A, Svedberg U, Nilsson E. Contact urticaria with anaphylactic reactions caused by occupational exposure to iridium salt. Contact Dermatitis 1995: 32: 14-17.

7. Angelini G. Linee guida sulla diagnostica della dermatite da contatto. G Ital Dermatol Venereol 1999: 134: 521-539.

8. Santucci B, Valenzano C, De Rocco M, Cristaudo A. Platinum in the environment: frequency of reactions to platinum-group elements in patients with dermatitis and urticaria. Contact Dermatitis 2000: 43: 333-338.

9. Vilanova X, Giménez-Camarasa J M. Experiencias para intentar aclarar una presunta acción sensibilizante del rhodio. Actas Dermosifilogr 1965: 56: 321-327.

10. Foti C, Amoruso A, Cassano N, Vena G A. Contact sensitization to nickel from rhodium-plated "nickelfree" earrings. Contact Dermatitis 2002: 46: 309.

Address:

L. Stingeni

Section of Clinical, Allergological and

Environmental Dermatology

Department of Medical and

Surgical Specialities

Policlinico Monteluce

Via Brunamonti

06100 Perugia

Italy

Tel: +390755731388

Fax: +390755783452

e-mail:dermalam@unipg.it
Natural rubber latex allergy: the impact on lifestyle and quality of life

V. J. Lewis ${ }^{1}$, M. M. U. Chowdhury ${ }^{1}$ and B. N. Statham ${ }^{2}$

${ }^{1}$ Welsh Institute of Dermatology, Cardiff, and ${ }^{2}$ Singleton Hospital, Swansea, UK

Key words: Dermatology Life Quality Index; healthcare workers; natural rubber latex allergy; occupational; quality of life.

We have conducted a postal survey of patients with natural rubber latex (NRL) allergy, to assess their quality of life and any lifestyle changes following diagnosis.

\section{Patients and Methods}

50 consecutive NRL-allergic patients, seen in 2 specialist contact dermatitis centres in Swansea and Cardiff, were sent a postal questionnaire. All had had a positive prick test to NRL during 1994-2003. The questionnaire enquired about occupation, symptoms, associated food allergies and lifestyle changes since diagnosis. Patients also completed the Dermatology Life Quality Index (DLQI) (1) as experienced before and after their diagnosis.

\section{Results}

$36 / 50(72 \%)$ of patients responded. Their mean age was 36 years (range 22-56 years). $50 \%$ of patients had suspected latex allergy before their diagnosis, and some had experienced up to 10 years of symptoms prior to their positive latex allergy test.

$72 \%$ were in regular contact with latex $-61 \%$ were healthcare professionals, $42 \%$ nurses. Of the $72 \%$ in regular contact with latex, all had switched to latex-free gloves and $85 \%$ reported subsequent improvement in their symptoms. 58\% felt 
that their employer had been helpful, and $25 \%$ had changed their job profile as a direct result of their latex allergy.

$39 \%$ reported an associated food allergy to banana (10 patients), kiwi fruit ( 7 patients), avocado (4 patients) and potato ( 3 patients). Of the 32 patients who had visited their doctor or dentist following diagnosis, $66 \%$ found them to be well informed about latex allergy.

Patients were questioned about the effect of their allergy on their work, hobbies, social life, relationships, contraception and diet, rating their responses 'none', 'mild', 'moderate' and 'severe'. Work and contraception caused most 'severe' impact, with $39 \%$ and $44 \%$ in this category, respectively. The DLQI score before diagnosis was 17.9/30 and after diagnosis was $10.9 / 30$.

\section{Discussion}

A recent large survey of healthcare workers in Wales estimated the prevalence of NRL allergy to be $0.56 \%$ (2). Overall, our study confirms the severe impact this condition can have on quality of life. DLQI scores after diagnosis showed a value of 10.9/30, with a value over 10 considered significant requiring possible active intervention (3).

$33 \%$ of patients had experienced difficulties when visiting their doctor or dentist, sometimes requiring return visits when gloves were available, having to explain the necessary precautions, and even supplying their own latex-free gloves.

Of most concern was the relatively high proportion $(25 \%)$ of patients who felt the need to change the nature of their work as a direct result of their NRL allergy. This varied between a full career change, transfer from hospital to community nursing and a job change within the hospital to a relatively 'latex-free' environment. In contrast, a study of 71 Finnish healthcare workers with latex allergy showed an excellent prognosis (4). At a median 3-year follow-up, none had changed the nature of their work as a result of their condition. We can only explain the reason for our findings to be a lack of support from employers, as $42 \%$ were thought not to have assisted their employees. In addition, some employers may delegate risk assessment of their staff to line man- agers, whose poor understanding of NRL allergy can lead to unreasonable working restrictions on those affected.

Our study has demonstrated that doctors, dentists and employers still display a lack of knowledge in dealing with NRL allergy. Their further education and increased awareness should improve quality of life in those patients whose condition, as we have shown, causes many of them considerable distress.

\section{References}

1. Finlay A Y, Khan G K. Dermatology Life Quality Index (DLQI): a simple practical measure for routine clinical use. Clin Exp Dermatol 1994: 19: $210-216$

2. Chowdhury M M U, Statham B N. Natural rubber latex allergy in a health-care population in Wales. Br J Dermatol 2003: 148: 737-740.

3. Hongbo Y, Thomas C L, Harrison M A, Salek M S, Finlay A Y. Translating the science of quality of life into practice: what do Dermatology Life Quality Index scores mean? $\mathrm{Br} J$ Dermatol 2004: 151 (Suppl. 68): 21-26.

4. Turjanmaa K, Kanto M, Kautiainen H, Reunala T, Palosuo T. Long-term outcome of 160 adult patients with natural rubber latex allergy. $J$ Allergy Clin Immunol 2002: 110: S70-S74.

\section{Address:}

Dr V.J. Lewis

Welsh Institute of Dermatology

University Hospital of Wales

Heath Park

Cardiff

CF14 $4 X N$

$U K$

Tel: +442920747747

Fax: +442920745161

e-mail:vjlewis65@hotmail.com

The sensitizing potential of iodopropynyl butylcarbamate in the local lymph node assay

\section{Jörg Siebert}

Schülke \& Mayr GmbH, Research \& Development, Germany

Key words: allergic contact dermatitis; cosmetics; iodopropynyl butylcarbamate; local lymph node assay; preservatives; sensitizing potential.
In the last few years an increasing number of cases of allergic contact dermatitis from iodopropynyl butylcarbamate (IPBC), used as preservative in personal care products, have been reported (1-3). Meanwhile, the local lymph node assay (LLNA) is a validated and accepted test method (OECD 429) to determine sensitization potential. Whereas for several other preservatives the allergenic potentials have been determined by the LLNA (4), such data for IPBC is still missing.

\section{Materials and Methods}

IPBC (batch no. 301506 from Skyanide Chem., Prien, Germany) was tested according to OECD Guideline 429 (5). 4 concentrations of the test item $[10,5,1$ and $0.1 \%(\mathrm{w} / \mathrm{v})]$ were chosen. The vehicle was AOO $[3+1$ (v/v) acteone/olive oil]. Methyldibromo glutaronitrile (MDBGN) 10\% and 5-chloro-2-methyl-4-isothiazolin3-one/2-methyl-4-isothiazolin-3-one (CMI/MI) $0.1 \%$ in $\mathrm{AOO}$ served as positive controls. The vehicle (AOO) served as negative control.

Each mouse was treated by topical application of the test item to the entire dorsal surface of each ear $\times 1$ daily over 3 consecutive days. 5 days after the first topical application, all mice were injected intravenously with ${ }^{3} \mathrm{H}$-methyl thymidine. Approximately $5 \mathrm{hr}$ after injection, all mice were killed and the draining auricular lymph nodes were excised and weighed individually for each animal. After the weighing, a single-cell suspension of the lymph node cells for each animal was prepared for counting radioactivity.

The proliferative response of lymph node cells was calculated as the ratio of ${ }^{3} \mathrm{H}$-methyl thymidine incorporation into lymph node cells of test group animals, relative to that recorded for control group animals. A stimulation index (SI) (ratio of test item/negative control) was calculated for each concentration.

This study was conducted in compliance with Good Laboratory Practice Regulations.

\section{Results}

The mean of the lymph node weights and the SI for each test item and concentration are shown in Table 1. 
Table 1. Stimulation index and weight of lymph nodes (mean \pm SD) of different concentrations of iodopropynyl butylcarbamate (IPBC) and methyldibromo glutaronitrile (MDBGN) and 5-chloro-2-methyl-4-isothiazolin-3-one/2-methyl-4-isothiazolin-3-one $(\mathrm{CMI} / \mathrm{MI})$ as positive controls in the local lymph node assay (LLNA)

\begin{tabular}{lccc}
\hline Test item & Concentration (\%) & Stimulation index (SI) & Weight of lymph nodes (mg) \\
\hline IPBC & 0.1 & $0.7 \pm 0.3$ & $2.8 \pm 0.4$ \\
IPBC & 1 & $3.4 \pm 1.4$ & $5.5 \pm 0.6$ \\
IPBC & 5 & $4.2 \pm 1.8$ & $5.3 \pm 0.3$ \\
IPBC & 10 & $12.0 \pm 3.4$ & $5.8 \pm 0.8$ \\
MDBGN (positive control) & 10 & $6.1 \pm 1.3$ & $4.5 \pm 0.5$ \\
CMI/MI (positive control) & 0.1 & $8.7 \pm 1.3$ & $4.3 \pm 0.5$ \\
Negative control & & 1.0 & $2.6 \pm 0.3$ \\
\hline
\end{tabular}

The EC3 value (theoretically derived by linear interpolation) was at a concentration of $0.87 \%$ IPBC. On daily clinical observation the animals did not show any visible clinical symptoms.

\section{Discussion}

The SI for the positive controls (MDBGN, $\mathrm{CMI} / \mathrm{MI})$ are in the range of the known data (4). According to the recommendations of the ECETOC (6), IPBC has to be classified as a moderate-to-strong sensitizer with a EC3 value of $0.87 \%$. This value is below that of MDBGN $(\mathrm{EC} 3=5.2 \%)$, which is regarded as moderate sensitizer, but above that for $\mathrm{CMI} / \mathrm{MI}(\mathrm{EC} 3=0.05 \%)$, which is considered a strong contact allergen (4).

The SIs were also confirmed by the second endpoint, the weight of the single lymph nodes. There is a clear increase in weights for all doses which showed sensitizing properties at the determination of radioactivity (Table 1).

A moderate sensitizing potential for IPBC was recorded by Zissu et al. (7) in the guinea pig maximization test, where 6 of 19 treated animals showed a positive skin reaction. This result corresponds fairly well with the LLNA predicting moderate-to-strong sensitizing properties.

Given the increasing use of IPBC in cosmetic leave-on products as a substitute for MDBGN, which will be prohibited for use in leave-on products from 2005, close surveillance of its sensitizing frequency should take place in the future. The widespread presence of IPBC currently in moist tissues for personal care incurs further risk, as witnessed by its predecessor MDBGN, which produced a number of intial reports of contact dermatitis in the early 1990s, mainly in moist toilet tissues (8), followed by increasing reports in recent years due to its frequency of use (9).

\section{Acknowledgements}

I thank Bioservice Scientific Laboratories GmbH (Planegg, Germany) for conducting the tests.

\section{References}

1. Bryld L E, Agner T, Menné T. Allergic contact dermatitis from 3-iodo-2-propynyl-butylcarbamate - an update. Contact Dermatitis 2001: 44: 276.

2. Schnuch A, Geier J, Brasch J, Uter W. The preservative iodopropynyl butylcarbamate: frequency of allergic reactions and diagnostic considerations - Results from the IVDK. Contact Dermatitis 2002: 46: 153.

3. Badreshia S, Marks J M Jr. Iodopropynyl butylcarbamate. Am J Contact Dermat 2002: 13: 77-79.

4. Basketter D A, Evans P, Gerberick G F, Kimber I A N. Factors affecting thresholds in allergic contact dermatitis: safety and regulatory considerations. Contact Dermatitis 2002: 47: 1-6.

5. OECD Guidelines for Testing of Chemicals. Number 429, "Skin Sensitization: Local Lymph Node Assay". (Adopted: 24th April 2002).

6. ECETOC. Technical Report No. 87, Contact Sensitization: Classification According to Potency 2003.

7. Zissu D. The sensitizing potential of various biocides in the guinea pig maximization test. Contact Dermatitis 2002: 46: 224-227.

8. De Groot A C, Weyland J W. Contact allergy to methyldibromogluraronitrile in the cosmetics preservative Euxyl K 400. Am J Contact Dermat 1991: 2: 31-32.

9. Wilkinson J D, Shaw S, Andersen K E et al. Monitoring levels of preservative sensitivity in Europe - A 10-year overview. Contact Dermatitis 2002: 46: 207-210.
Address:

Jörg Siebert

Schülke \& Mayr GmbH

Research \& Development

Robert-Koch-Strasse 2

22851 Norderstedt

Germany

Tel: +494052100534

Fax: +494052100577

e-mail: joerg.siebert@schuelke-mayr.com

Patch testing with the Indian standard series in New Delhi

Vinod K Sharma, Gomathy Sethuraman, Taru Garg, Kaushal K Verma and M Ramam

Department of Dermatology \& Venereology, All India Institute of Medical Sciences, New Delhi, India

Key words: Indian standard series; nickel; parthenium; patch test.

Allergic contact dermatitis (ACD) is an abnormal reaction pattern of the skin in response to various external agents, which is mediated by cellmediated immune response (1). The prevalence of ACD ranges from 1.5 to $5.5 \%$ of the general population (2). In India, it accounts for $10-15 \%$ of dermatological patients (3). The American Academy patch test kit and the European standard series (ESS) have already been well established for patch testing (4). The Indian standard series (ISS), consisting of 28 allergens approved by the Contact and Occupational Dermatoses Forum of India (CODFI), has been made available in India for more than 5 years. The list of allergens in the ISS is similar to that of the ESS, with the exception of primin and the sesquiterpene lactone mix (SL). Previous Indian studies showed 
Table 1. Age and sex distribution of patients with frequency of positive patch tests

\begin{tabular}{lcclcc}
\hline & \multicolumn{2}{l}{ Number of patient $[n(\%)]$} & & \multicolumn{2}{l}{ Number of positives $[n(\%)]$} \\
\cline { 2 - 3 } Age in years & Male & Female & & Male & Female \\
\hline Up to 20 & $7(5.4)$ & $11(12)$ & & $5(6.5)$ & $8(12.6)$ \\
$21-40$ & $51(39.5)$ & $51(56)$ & & $26(33.8)$ & $36(57.1)$ \\
$41-60$ & $53(41)$ & $24(26)$ & & $36(46.7)$ & $17(26.9)$ \\
$>60$ & $18(13.9)$ & $5(5.5)$ & & $10(13)$ & $2(3.2)$ \\
Total & $129(58.9)$ & $91(41.4)$ & & $77(55)$ & $63(45)$ \\
\hline
\end{tabular}

Table 2. Patterns of allergic contact dermatitis

\begin{tabular}{llc}
\hline Pattern & $\begin{array}{l}\text { Male } \\
{[n(\%)]}\end{array}$ & $\begin{array}{l}\text { Female } \\
{[n(\%)]}\end{array}$ \\
\hline Airborne & $35(27.1)$ & $20(21.9)$ \\
Hands & $20(15.5)$ & $25(27.5)$ \\
Feet & $10(7.7)$ & $14(15.4)$ \\
Hands and feet & $26(20.1)$ & $8(8.8)$ \\
Others & $38(29.4)$ & $24(26.4)$ \\
\hline
\end{tabular}

that primin is not the common sensitizer that it is in the Western world and that the SL mix is not an adequate screen for parthenium sensitivity (3). Additional allergens in the ISS are polyethylene glycol 400, chinoform and an aqueous extract of the plants parthenium, xanthium and chrysanthemum.

\section{Materials and Methods}

Patch testing in 220 patients (129 male, 91 female) aged between 11 and 70 years with suspected ACD was done with the ISS. Plants (aqueous and acetone extract of parthenium and aqueous extract of xanthium and chrysanthemum) (5) were tested in suspected patients especially with airborne contact dermatitis. The technique was carried out and scored as per the standard guidelines (3).

\section{Results}

The age and sex distribution of patients with positive patch test reactions and the different clinical pattern of contact dermatitis are shown in Tables 1 and 2, respectively. The 28 allergens of the ISS and the number of patients with positive reactions are listed in Table 3.140 patients $(63.6 \%)$ [male $77(55 \%)$, female $63(45 \%)$ ] showed 1 or more positive reactions. The maximum number of positive reactions was recorded in the age group of 21-40 years in females $(57.1 \%)$ and $41-60$ years in males $(46.7 \%)$. The most frequent sensitizers were nickel sulfate $(31.4 \%)$, parthenium $(26.4 \%)$, potassium dichromate $(15.7 \%)$, cobalt chloride $(12.1 \%)$, fragrance mix $(11.4 \%)$, nitrofurazone $(10.7 \%)$ and colophony $(9.3 \%)$. Neomycin, mercapto mix and mercaptobenzothiazole showed positive reactions in $7.8 \%$ each. Positive patch test reactions were found to be relevant in 115 $(82.1 \%)$ patients.

Table 3. Indian standard series (ISS) allergens and their positivity

\begin{tabular}{|c|c|c|c|c|}
\hline Sr. number & Allergens & Total $[n(\%)]$ & Male & Female \\
\hline 1 & Potassium dichromate $0.5 \%$ & $22(15.7)$ & 19 & 3 \\
\hline 2 & Neomycin sulphate $20 \%$ & $11(7.8)$ & 7 & 4 \\
\hline 3 & Cobalt chloride $1 \%$ & $17(12.1)$ & 8 & 9 \\
\hline 4 & Benzocaine $5 \%$ & $6(4.3)$ & 3 & 3 \\
\hline 5 & Formaldehyde $1 \%$ & $3(2.1)$ & 0 & 3 \\
\hline 6 & 4-phenylenediamine $1 \%$ & $9(6.4)$ & 4 & 5 \\
\hline 7 & Parabens $15 \%$ & $2(1.4)$ & 2 & 0 \\
\hline 8 & Nickel sulphate $5 \%$ & $44(31.4)$ & 12 & 32 \\
\hline 9 & Colophony $20 \%$ & $13(9.3)$ & 7 & 6 \\
\hline 10 & Gentamicin $20 \%$ & $3(2.1)$ & 3 & 0 \\
\hline 11 & Propylene glycol 2\% & $7(5)$ & 6 & 1 \\
\hline 12 & Mercaptomix 2\% & $11(7.8)$ & 5 & 6 \\
\hline 13 & Epoxy resin $1 \%$ & $4(2.8)$ & 2 & 2 \\
\hline 14 & Fragrance mix $8 \%$ & $16(11.4)$ & 9 & 7 \\
\hline 15 & Mercaptobenzothiazole $2 \%$ & $11(7.8)$ & 6 & 5 \\
\hline 16 & Nitrofurazone $2 \%$ & $15(10.7)$ & 10 & 5 \\
\hline 17 & Polyethylene glycol (400) 100 & $4(2.8)$ & 4 & 0 \\
\hline 18 & Chlorocresol 1\% & $4(2.8)$ & 3 & 1 \\
\hline 19 & Lanolin alcohol 30\% & $1(0.7)$ & 1 & 0 \\
\hline 20 & Balsam of Peru $25 \%$ & $3(2.1)$ & 1 & 2 \\
\hline 21 & Thiuram mix $1 \%$ & $7(5)$ & 4 & 3 \\
\hline 22 & Chinoform 3\% & $4(2.8)$ & 3 & 1 \\
\hline 23 & Kathon CG $0.67 \%$ & $2(1.4)$ & 1 & 1 \\
\hline 24 & Ethylenediamine hydrochloride $1 \%$ & 0 & 0 & 0 \\
\hline 25 & Black rubber mix $0.6 \%$ & $2(1.4)$ & 1 & 1 \\
\hline 26 & P-tert butylphenol 1\% & $3(2.1)$ & 1 & 2 \\
\hline 27 & Quaternium $151 \%$ & $1(0.7)$ & 1 & 0 \\
\hline \multirow[t]{4}{*}{28} & Plant allergens & & & \\
\hline & Parthenium hysterophorus & $37(26.4)$ & 25 & 12 \\
\hline & Xanthium & $11(7.8)$ & 5 & 6 \\
\hline & Chrysanthemum & $6(4.2)$ & 2 & 4 \\
\hline
\end{tabular}




\section{Discussion}

The commonest clinical pattern observed was airborne (parthenium) contact dermatitis. Pasricha (6), and Sharma and Kaur $(7,8)$ have previously reported a large number of such cases. In our earlier series (3) this was also the commonest pattern, in contrast to hand dermatitis in other series (9-11). Its preponderance in males $(63.63 \%)$ has also been observed earlier $(7,8,12)$. The figure of $63.6 \%$ of patients showing 1 or more positive reactions is comparable with the findings of El-Rab et al. (13), Singhal and Reddy (2), and Sharma and Chakrabarti (3) but higher than those of Zhang et al. (14) and Hammershoy (15).

Most of the Asian centres, namely Saudi Arabia (13), Beijing (14), Shanghai (16), Taipei (17) and Singapore (18), have also reported nickel as the commonest allergen, and it was the 2nd most common sensitizer in Hong Kong (19) and India $(3,4)$.

Parthenium was the 2nd most common allergen in the present series $(26.4 \%)$, whereas it was the most common sensitizer in 2 other series from India $(2,3)$. In a similar series of patch testing done with the ESS, parthenium sensitivity was seen in only $14 \%$ of patients. Such a low positivity could be due to the fact that the ESS contains only the SL mix as a screen for Compositae allergy (3), which is not adequate.

Potassium dichromate was the most frequent sensitizer in the previous report from Chandigarh, India (3), while it ranked 2 nd in all Asian centres (2, 4, 13-15) except Singapore (18) and Hong Kong (19), where the incidence of chromate sensitivity was extremely low, 2.7 and $1.6 \%$, respectively. Cobalt chloride was a frequent sensitizer in Saudi Arabia (13), Beijing (14) and Taipei (17), whereas it was seen in only $12.1 \%$ of our patients, which is almost similar to that of other Indian series $(2-4)$

Fragrance mix was the commonest allergen in Hong Kong (19) and 2nd most common in Taipei (17) and Singapore (18), whereas it was only the 5th most common sensitizer in our population, perhaps because of the difference in cultures.
In a series from Manipal, India (4), gentamicin showed the highest frequency of positivity, while in another report from India none of the patients showed positivity to topical antibiotics (2). Neomycin sensitivity was seen in $5 \%$ of the patients in a previous series (3). Such wide variation could be due to differences in prescription patterns.

In conclusion, the common contact sensitizers in Delhi, India are nickel, parthenium, chromate, cobalt and fragrance. Relevance of such positive patch test reactions was seen in $82.1 \%$ of patients, and hence, the ISS is suitable for diagnosis of most of our cases of ACD.

\section{References}

1. Bourke J, Coulson I, English J. Guidelines for care of contact dermatitis. $B r \quad J$ Dermatol 2001: 145: 877-885.

2. Singhal V, Reddy B S N. Common contact sensitizers in Delhi. J Dermatol 2000: 27: 440-445.

3. Sharma V K, Chakrabarti A. Common contact sensitizers in Chandigarh, India: a study of 200 patients with the European standard series. Contact Dermatitis 1998: 38: 127-131.

4. Shenoy S D, Srinivas C R, Balachandran C. Results of patch testing with standard series of allergens at Manipal. Indian J Dermatol Venereol Leprol 1994: 60: 133-135.

5. Sharma V K, Sethuraman G, Tejasvi T. Comparison of patch test contact sensitivity to acetone and aqueous extracts of parthenium hysterophorus in patients with airborne contact dermatitis. Contact Dermatitis 2004: 50: 230-232.

6. Pasricha J S. In: Contact Dermatitis in India, 2nd edn. New Delhi, The department of Science and Technology, 1988: 21-42.

7. Sharma V K, Kaur S. Contact dermatitis to plants in Chandigarh. Indian J Dermatol Venereol Leprol 1987: 53: 26-30.

8. Sharma V K. Patch testing with European Standard Series and compositae extracts in patients with air borne contact dermatitis. Contact Dermatitis 2001: 44: 49-50.

9. Agrup G. Hand eczema and other hand dermatoses in South Sweden. Acta Derm Venereol 1969: 49 (Suppl. 61): $73,74,84$.

10. Goh C L. An epidemiological comparison between occupational and non-occupational hand eczema. $\mathrm{Br} J$ Dermatol 1989: 120: 77-82.
11. Holness D L, Nethercott J R, Adams R M et al. Concomitant positive patch test results with standard screening tray in North America 1985-89. Contact Dermatitis 1995: 32: 289-292.

12. Mahajan V K, Sharma V K, Kaur I, Chakrabarthy A. Contact dermatitis in agricultural workers: role of common crops, fodder and weeds. Contact Dermatitis 1996: 35: 373-374.

13. El-Rab M O G, Al-Sheikh O A. Is the European standard series suitable for patch testing in Riyadh, Saudi Arabia? Contact Dermatitis 1995: 33: 310-314.

14. Zhang $X$ M, Niklasson B O, Shin Y L. Patch testing in cases of eczema and dermatitis in Beijing China. Contact Dermatitis 1991: 25: 224-229.

15. Hammershoy O. Standard patch test results in 3225 consecutive Danish patients from 1973 to 1977. Contact Dermatitis 1980: 6: 263-268.

16. Wang $X \mathrm{M}$, Lin $\mathrm{Y} \mathrm{F}$, Cheng $X \mathrm{~F}$, Zhang Y P, Ye M L. Patch testing with European standard series in Shanghai. Contact Dermatitis 1994: 30: 173-174.

17. Sun C C. Epidemiology of contact dermatitis in Taiwan. Proceedings 1st Pacific Symposium on Environmental and Occupational Dermatology. Singapore 22-24 June, 1991, pp 74.

18. Lim J T E, Goh C L, Ny S K, Wong W K. Changing trend in the epidemiology of contact dermatitis in Singapore. Contact Dermatitis 1992: 26: 321-326.

19. Lee T Y, Lam T H. Patch testing of 490 patients in Hong Kong. Contact Dermatitis 1996: 35: 23-26.

Address:

Dr V. K. Sharma

Department of Dermatology \& Venereology

All India Institute of Medical Sciences

New Delhi-110029

India

Tel: $+911126594224 / 26593217$

Fax: +911126588641/26588663

e-mail:aiimsvks@yahoo.com

Perineal allergic contact dermatitis due to tetracaine in a urological lubricant

Leticia Calzado Villarreal, Francisco Javier Ortiz de Frutos, Maria del Prado Sánchez Caminero and Francisco Vanaclocha Sebastián

Dermatology Department, Hospital 12 de Octubre, Ctra. Andalucía Km 5.400, 28041 Madrid, Spain 
Key words: caines; medicaments; perineal; tetracaines; vulvar.

Pruritus vulvae and ani are common complaints and their precise causes, including allergic contact dermatitis, are frequently misdiagnosed. Allergic contact vulvitis has rarely been reported from local anaesthetics such as tetracaine (amethocaine), though its allergenicity has been widely described (1-9).

\section{Case Report}

A 52-year-old woman with a 3-month history of pruritus vulvae came to our clinic. She had been repeatedly operated on because of urinary incontinence and frequently catheterized. She presented with erythematous scaly plaques on the vulva, perineal and perianal regions, and inner thighs. She had received treatment with topical antimycotics (clotrimazole) and corticosteroids, improving with the latter.

Patch tests with the GEIDC standard series, local anaesthetics, clotrimazole, povidone iodine and her own medicaments, including the urological lubricant Organon ${ }^{\circledR}$ (Organon Española, S.A., Barcelona, Spain) and some catheter samples were carried out. Positive reactions to caine mix, tetracaine hydrochloride and Organon $^{\circledR}$ ointment, at 3 and 7 days, were found. Para-phenylenediamine and other local anaesthetics tested were negative. Tetracaine hydrochloride was contained in the urological lubricant applied on the vesical catheter. The patient greatly improved when Organon $^{\circledR}$ was substituted with pet., and in fact, when, accidentally, a new nurse used the original lubricant again, the symptoms returned.

\section{Discussion}

Tetracaine (amethocaine) hydrochloride is a local anaesthetic derived from benzoic acid (esters of p-amino- benzoic acid type), often used to treat pruritus ani, haemorrhoids or pruritus vulvae (2). Also employed as a topical anaesthetic for eyes, ears, nose, throat or urethra (3), as in our case, it is rarely used for infiltration anaesthesia, as nowadays esters have been replaced by the amide group of anaesthetics (lidocaine, mepivacaine and bupivacaine) (4).

Tetracaine hydrochloride has been demonstrated to be a strong sensitizer (1-9). A Spanish study found positive patch tests to tetracaine in $1.2 \%$ of a large series of tested patients $(n=1328)$, which corresponded to almost $20 \%$ of those positive to caine mix (3). Most of these positivities were unrelated to occupation, though in 6 of 16 patients with positive patch tests to tetracaine an occupational origin could be found. These were mainly dentists with cracking and scaling of their finger pulps, as they used a spray containing tetracaine as pre-anaesthetic (tetracaine was considered the most frequent anaesthetic allergen among dentists 2 decades ago) $(3,4)$. Ophthalmologists, otorhinolaryngologists and even laserclinic nurses, can also be affected (6). It may infrequently cross-react with other anaesthetics of the ester group or para-phenylenediamine $(3,4,7)$.

Although lubricant ointments are widely used in urology, allergic contact dermatitis caused by these products, as in our case, is rare $(8,9)$. Besides, positivity to tetracaine hydrochloride was found in only 1 case of 45 women with vulvar problems (mainly pruritus vulvae) and 1 or more allergic reactions to patch testing, medicaments being the major source of allergens in these patients (1). Women with pruritus vulvae are frequently treated with multiple topical drugs, as was our patient, and are at risk of developing contact sensitivity (1).

\section{References}

1. Lewis $\mathrm{F}$ M, Harrington $\mathrm{C} I$, Gawkrodger D J. Contact sensitivity in pruritus vulvae: a common and manageable problem. Contact Dermatitis 1994: 31: 264-265.

2. Cronin E. Medicaments. In: Contact Dermatitis. Edinburgh: Churchill Livingstone, 1980: 193-202.

3. García-Pérez A, Conde Salazar L, Gimaraens D et al. La sensibilidad de contacto a ametocaína. Actas Dermosifiliogr 1981: 72: 441-448.

4. Conde-Salazar L, Llinas M G, Guimarens Det al. Occupational allergic contact dermatitis from amethocaine. Contact Dermatitis 1988: 19: 69-70.

5. Brandao F, Goossens A, Tosti A. Topical drugs. In: Textbook of Contact Dermatitis, 3rd edn. Rycroft R J G, Menné T, Frosch P J, Lepoittevin J-P (eds), Berlin, Springer-Verlag, 2001: 688-723.

6. Dawe R, Watt D, O'Neill S, Forsyth A. A laser-clinic nurse with allergic contact dermatitis from tetracaine. Contact Dermatitis 2002: 46: 306.

7. Lodi A, Ambonati M, Coassini A, Kouhdari M, Palvarini M, Crosti C. Contact allergy to 'caines' caused by anti-hemorrhoidal ointments. Contact Dermatitis 1999: 41: 221.

8. Sanchez-Pérez J, Cordoba S, FealCortizas C, García-Díez A. Allergic contact balanitis due to tetracaine (amethocaine) hydrochloride. Contact Dermatitis 1998: 39: 268.

9. Fernandez-Redondo V, Leon A, Santiago T, Toribio J. Allergic contact dermatitis from local anaesthetic on periostomal skin. Contact Dermatitis 2001: 45: 358.

Address:

Leticia Calzado Villarreal

Dermatology Department

Hospital 12 de Octubre

Ctra. Andalucía Km 5.400

28041 Madrid

Spain

Tel: +34913908302

Fax: +34913908302

e-mail:leti_cv@yahoo.es 